\title{
Qualitative Survey Assessment of Bike Share Programs on College Campuses
}

\author{
Cynthia M. Ferrara, Lauren Bennett, Michelle Bracci, Rachel Bromberg, Allison Fahey, and \\ Katherine Muise \\ University of Massachusetts Lowell, Physical Therapy Department, Exercise Physiology \\ Program
}

\begin{abstract}
Background: Many college campuses have implemented bike share programs. These programs may be important to reduce vehicle traffic and increase physical activity. Purpose: The purpose of this study was to identify issues and possible solutions for a successful campus bike share program. Methods: Study design: Qualitative. An online survey link was sent to 111 campus bike share coordinators in the Spring 2014. Twenty-five (22.5\%) completed the survey. Answers to multiple choice questions were summarized using descriptive statistics. Answers to open-ended questions were reviewed and a list of themes was developed. Results: The majority of respondents represented large universities (56\%) in urban areas (76\%) with high vehicle traffic (72\%). Although $84 \%$ considered their campus safe for biking, only 40\% reported designated bike lanes. Most programs allowed people to sign out a bike for 24 hours or less (56\%). The main problems were damage to bikes and on-time returns. Recommendations included designated mechanics for quick repairs, high quality bikes, user accountability, and user and staff training. Conclusion: Major issues and solutions were identified for campus bike share programs. Additional research needs to examine how these can be used to create successful bike share programs and how these programs might increase physical activity.
\end{abstract}

(c) 2015 Californian Journal of Health Promotion. All rights reserved. Keywords: College campuses, physical activity, bike share programs

\section{Introduction and Purpose}

College campus bike share programs are often touted as an environmentally responsible alternative to driving or taking shuttles, reducing the overall carbon footprint. Bicycling can reduce traffic and alleviate the need for more parking spaces, as well as promote physical activity (Kumar, Teo, \& Odoni, 2011; Rissel, Mulley, \& Ding, 2013). It is well established that increased physical activity is beneficial to overall health and may reduce the risk of chronic diseases (Andersen, Schnohr, Schroll, \& Hein, 2000). In addition, evidence suggests that bicycling may be associated with reduced weight gain and mortality. With the incidence of overweight and obesity in college students at 3035\% (Huang, Harris, Lee, Born, \& Kaur, 2003), promoting physical activity may have a significant impact on weight gain and overall health of college students. As more colleges implement a bike share program, it is important to consider best practices for a successful and sustainable bike share program and how these programs can encourage physical activity.

Recent reports suggest key factors to consider when developing a community bike share program. Engaging the community in the development process is an important step to creating a successful and sustainable program (Webster \& Cunningham, 2010; Stewart, Johnson, \& Smith, 2013). Planning for bikes at multiple convenient locations is also important. In addition, a plan to minimize theft and vandalism of the bikes is key to the success of the program (DeMaio, 2009; Kumar et al., 2011; Molina-Garcia, Castillo, Queralt, \& Sallis, 2015). Special consideration must be placed on the infrastructure, including bike lanes and special intersection modifications (Kumar et al., 2011). Helmet availability and proper maintenance of the bikes will help to increase bike safety (Kumar et al., 2011). These factors, 
important to the success of community bike share programs, may also be crucial to successful bike share programs on college campuses. Additional research will be important, since the characteristics of the population on a college campus may be different and thus, affect what features may be important for success of a bike share program.

To our knowledge, no studies have specifically examined what is needed to create a successful campus bike share program. Thus, the purpose of this study was to identify the common issues and possible solutions to creating a successful campus bike share program. This information will inform future research regarding how a successful bike share program might successfully increase physical activity levels among college and university students.

\section{Methods}

\section{Study design}

A qualitative study was designed to identify issues and solutions to creating a successful campus bike share program. The study was approved by the Institutional Review Board at the University of Massachusetts Lowell.

\section{Sample}

Campus bike share coordinators were identified via internet searches for "campus bike share programs". The searches identified news articles and websites, with references to campus bike share programs in the United States. Study investigators were then able to identify one hundred and eleven bike share coordinators and their contact information. Twenty-five coordinators completed the questionnaire, yielding a $22.5 \%$ return rate.

\section{Measures}

A questionnaire was developed to identify issues and possible solutions to creating a successful campus bike share program. Questions were developed based on a review of the literature and discussion with students and the campus bike share coordinator. Questions included general demographic information about the campus community, including the number of students and the campus environment, and the bike share program. The questionniare also included two qualitative questions addressing major problems and any recommendations for those planning a new bike share program.

\section{Procedures}

An introduction and the online link to the questionnaire was sent to 111 campus bike share coordinators via email in the Spring 2014. Approximately one month after the initial contact, a reminder email was sent, again inviting participation in the study. The surveys were annonymous, so coordinators could not be identified.

\section{Analyses}

Frequencies and percentages for multiple choice questions were calculated using SPSS. Answers to open-ended questions were reviewed by three investigators and themes were identified by each investigator. The themes were compared and a final list was developed. Two of the investigators then used the final list to code the open-ended questions. A third investigator reviewed the answers to the questions and approved the coding implementation.

\section{Results}

Fifty-six percent of survey respondents worked at universities of more than 10,000 students, $16 \%$ worked at universities between 5,00010,000 students, and $28 \%$ worked at universities of less than 5,000 students. Seventy-six percent of the campuses were located in urban areas as opposed to rural and $72 \%$ indicated there was a lot of motor vehicle traffic in and around the campus. Although $84 \%$ considered their campus safe for biking, only $40 \%$ reported that the campus had designated bike lanes.

For $88 \%$ of the campuses, this was their first bike share program. Forty-eight percent of the programs were in operation for 3-5 years. Most programs were run by student staff (68\%), and $96 \%$ reported that mostly students sign out the bikes. Most programs allowed people to sign out a bike for 24 hours or less (56\%), while 36\% allowed people to sign out a bike for a semester or term, and only $8 \%$ allowed people to sign out a bike for an entire year. Sixty-eight percent 
provided helmets to those who signed out bikes and $88 \%$ provided safety information. Although 96\% provided bike locks, theft was still a major issue. Coordinators indicated that the majority of the thefts were due to improper locking of the bikes.

Table 1 presents themes and relevant quotes related to major problems affecting the bike share program. Damage to the bikes and cost for repair/replacement of bikes can be prohibitive for a new program. Many coordinators indicated that participants did not always let staff know that a bike was damaged when they returned the bike. This affected the availability of quality bikes to meet the demand. Enforcing on time bike returns was also a major issue. Finding ways to increase accountability for late returns and damaged bikes will be essential to the success of a program.

\section{Table 1.}

Common Issues Affecting Campus Bike Share Programs.

Question: What do you consider the major problem affecting your bike share program?

Themes and relevant quotes

Damage to bikes and cost for repairs $(n=10)$

“...daily rentals are ridden hard and need a fair amount of repairs. This repair is done by student volunteers and they [do not have time] to repair a bike.”

Late returns and accountability $(\mathrm{n}=7)$

"We are having issues charging people for late returns so people see no reason to take special care to bring the bike back. And we have no way to make them accountable"

Staff training $(\mathrm{n}=6)$

"The students that sign out the bikes are Residential Life Wellness staff, and we have had difficulties in training them to properly maintain bikes (i.e., ensure tires are inflated before a student takes the bike out, checking for damage, reporting damage, etc.)”

Funding $(\mathrm{n}=5)$

"A major issue is obtaining funds to start, maintain, and expand a bike share program."

"It takes time and money to run programs of this nature... we have limited funding available to expand the program when we are simply relying on grants.”

Availability of bikes ( $\mathrm{n}=5)$

"The program relied heavily on the honor system. Participants were asked to follow certain guidelines, such as leaving bikes in a certain area, checking them for maintenance and contacting the bike co-op if it was needed, and freeing up the bike for other participants within a certain time period.”

“...the main problem is lack of bike availability due to irregular maintenance. We have high demand but often low supply."

Lack of training for staff and students who helped with the operation of the bike share program was also an issue for many programs. Staff may not report bike issues to supervisors or may not adequately check bikes at check-in. This may result in repair issues not being immediately addressed, which will then limit the number of bikes available for rental.

Table 2 presents relevant themes and quotes related to recommendations for those planning a new campus bike share program. One suggestion was to investigate campus interest prior to starting a program. This would help in identifying who might be interested in using the bikes and what they might be willing to pay for such a program. Two respondents suggested starting with a small program before investing time and money in a larger program. To reduce the impact of damaged bikes might have on the program, a continuous supply of mechanics, better quality and a variety of bikes, and longer rentals may be important. One program coordinator mentioned that new bikes are not always the key to success. A variety of bikes with different features and colors may be 
important. People can then choose the bike that they want, which might mean they will take better care of the bike and be more accountable with on-time returns. In addition, long-term rentals may give students the feeling of responsibility as they will be the ones to suffer if they damage the bike.

Table 2.

Recommendations for New Campus Bike Share Programs.

\begin{tabular}{l}
\hline Question: What recommendations do you have for other colleges or universities that are planning a new bike share program? \\
\hline Themes and relevant quotes \\
"Ariety of bikes available (n=9) \\
exclusively donated used bikes that we fix up and turn into rental bikes. They may not be shiny and new, but every bike is \\
unique. Community members who come in and rent a bike are always excited that they can have a choice about the color and \\
style of bike they will be riding around on.” \\
Mechanics available to repair bikes (n=5) \\
"A steady supply of mechanics is absolutely necessary. Most frequently a mechanic is only willing to give two hours a week \\
or so having upwards of ten hours for a bike share of 30 bikes is necessary.” \\
Long term rentals (n=5) \\
"Make the bikes available for long term check out and make them look nice. We have found that these two steps had very \\
positive impacts on how our students treat the bicycles. Short term check out of ratty looking bikes leads to lots of misuse and \\
abuse.”
\end{tabular}

Training for staff and users $(\mathrm{n}=12)$

"Get students involved in the maintenance because there is a lot to learn in terms of hands-on education that is not normally part of a college education. Have basic bike skills classes so people can become educated and safe cyclists.”

"The lack of bike knowledge among our users (largely international students) leads to our bikes not being treated well”

Solutions to reduce late returns and thefts $(\mathrm{n}=10)$

"Make students who rent the bikes liable for lost or stolen bikes and for excessive damages by charging them as appropriate. We place holds on student accounts and the money goes to the bike shop."

"Once members know that you will collect the damages or replacement costs for theft or damage, bikes become less likely to go missing or to be misused."

Maintaining a clear record of who signed out the bike and placing a hold on the user's account if the bike is not returned may reduce late returns and theft (Table 2). One respondent suggested that the bikes could be checked out similar to borrowing a book from the library, although others suggested an online or automated registration system. The extra cost of such a system may be worth the initial financial investment.

Another important recommendation was education of students and staff (Table 2). Educating staff on proper check out and check in procedures will help with accurate record keeping. Providing training on basic bike skills, including how to properly lock a bike to a rack, will promote safe biking habits and may reduce thefts.

\section{Discussion}

Many colleges provide quality bikes for students, faculty and staff as part of a campus bike share program. The purpose of this study was to survey campus bike share coordinators and identify what are the common issues and some possible solutions. This information may help to develop strategies for successful and sustainable campus bike share programs, promote physical activity, and improve the health of the campus community.

Respondents suggested that universities should carefully evaluate the interest in a bike share program prior to investing time and money in developing a program. Campuses should 
consider conducting focus groups or surveys to evaluate interest and, more importantly, how much people would pay to support a bike share program. Although starting small may be an approach, too few bikes may limit the success of the program (New York City Department of City Planning, 2009). Campus coordinators should consider carefully the pluses and minuses of starting with a small program before approving this option.

In addition, respondents suggested that training and education should be a major component of a campus bike share program. Staff need to be trained about check-out and check-in procedures. This type of training will help in documenting missing bikes and the need for repairs. Training may also be important for those who borrow a bike. Required training for participants might cover safe biking habits and basic rules of the road. Staff can also educate participants on how biking and other modes of active transport can increase daily exercise, which may improve fitness, body composition, and overall health.

The major issues were damaged or stolen bikes and on-time returns. Many of the new programs utilize new technologies to help with these issues. A smart card system will make it easier to charge users for damage and late returns. In addition, tracking systems make it easier to locate missing bikes. Although it may increase the cost, programs may benefit from the use of technology (DeMaio, 2004).

\section{Study Limitations}

Only 25 out of 111 coordinators responded to the online survey (22.5\%). Although this is similar to the average response rate for emailed surveys (25-30\%, Fincham, 2008), it is still relatively low and may not accurately reflect all campus bike share programs. The majority of respondents (72\%) worked at medium- and large-sized universities (5000 students or greater). This might suggest that the results are representative of universities of this size, and issues and solutions may differ in smaller campus communities. In addition, a large percentage of the respondents worked at universities that were in urban areas, with significant motor vehicle traffic. Small college towns or universities in rural areas may have different concerns and issues than those in the current study (Rissel et al., 2013). Future research will need to examine these differences.

\section{Conclusions}

In conclusion, campus bike share coordinators identified availability, damage, and theft as major issues facing campus bike share programs. Possible solutions include utilizing new technologies to track users and location of bikes, as well as training of staff and users. Consideration of these issues may help campuses to create successful and sustainable campus bike share programs that promote physical activity and improve the health of the campus community.

\section{References}

Andersen, L., Schnohr, P., Schroll, M., \& Heim, H. (2000). All-cause mortality associated with physical activity during leisure time, work, sports, and cycling to work. Archives of Internal Medicine, 160: 1621-1638.

DeMaio, P. (2004). Will smart bikes succeed as public transportation in the United States? Journal of Public Transportation, 7(2), 1-15.

DeMaio, P. (2009). Bike-sharing: History, impacts, models of provision, and future. Journal of Public Transportation, 12(4), 41-56.

Fincham, J.E. (2008). Response rates and responsiveness for surveys, standards, and the Journal. American Journal of Pharmaceutical Education, 72(2): Article 43.

Huang, T.T.K., Harris, K.J., Lee, R.E., Nazir, N., Born, W., \& Kaur, H. (2003). Assessing overweight, obesity, diet, and physical activity in college students. Journal of American College Health, 52(2), 83-86.

Kumar, A., Teo, K.M., \& Odoni, A. (2011). A systems perspective of cycling and bike-sharing systems in urban mobility. (Doctoral dissertation). Retrieved from 
http://ares.lids.mit.edu/fm/documents/A\%20Systems\%20Perspective\%20of\%20Cycling \%20and\%20Bike-sharing\%20Systems\%20in\%20Urban\%20Mobility.pdf.

Molina-Garcia, J., Castillo, I., Queralt, A., \& Sallis, J. (2015). Bicycling to university: evaluation of a bicycle-sharing program in Spain. Health Promotion International, 30(2), 350-358.

New York City Department of City Planning. (2009). Bike-share opportunities in New York City. Available at: www.nyc.gov/html/dcp/pdf/transportation/bike_share_complete.pdf. Accessed June 15, 2015.

Rissel, C., Mulley, C., \& Ding, D. (2013). Travel mode and physical activity at Sydney University. International Journal of Environmental Research and Public Health, 10(8), 3563-3577.

Stewart, K.S., Johnson, D.C., \& Smith, W.P. (2013). Bringing bike share to a low-income community: Lessons learned through community engagement, Minneapolis, Minnesota. Preventing Chronic Disease, 10 (Aug 15), 120274.

Webster, K.M., \& Cunningham, C.J.L. (2010). Preparing for bike-sharing: Insight from focus groups and surveys, Chattanooga, Tennessee. Health Promotion Practice, 14, 62-68.

$\underline{\text { Author Information }}$

*Cynthia M. Ferrara

Merrimack College

Department of Health Sciences

315 Turnpike St.

North Andover, MA 01854

978-837-5354

ferraracm@merrimack.edu

* corresponding author 